\title{
Research on Configuration Optimization of Multi- echelon Inventory Based on Component Commonality
}

\author{
Lijun Qiu${ }^{1}$, Linyu Fu², Qi Dong², Chongyi Liu $^{2, *}$, Kun Xian³ and Xinhua Weng ${ }^{4}$ \\ ${ }^{1}$ Naval Aeronautical and Astronautical University, Yantai 264001 Shandong, China \\ ${ }^{2}$ Naval Aeronautical and Astronautical University, Coast Defense Troop Institute, Yantai 264001 Shandong, China \\ ${ }^{3} 91183$ PLA, Qingdao 266000 Shandong, China \\ ${ }^{4} 91515$ PLA, Sanya 572061 Hainan, China \\ ${ }^{*}$ Corresponding author
}

\begin{abstract}
In view of the repairable spare parts, considering the actual situation that component commonality exists in warship equipment, the requirements of spare parts and sites in all levels are modified. A multi-echelon configuration model of common parts based on METRIC theory is established. The marginal optimization algorithm is used to obtain spare parts. The optimal supply support schemes prove that this model improves the model evaluation accuracy and reduces the total configuration cost under the premise of meeting the requirements of support index, which provides a theoretical basis and decision support for the current equipment to promote the use of component commonality.
\end{abstract}

Keywords—spare part; component commonality; multi-echelon configuration strategy

\section{INTRODUCTION}

Failure modes and fault characteristics are not single because of various types of spare parts, so it is difficult to achieve the best effect through relying on single maintenance mode or maintenance strategy. Therefore, according to the actual situation that different types of spare parts adopt different maintenance strategies, it is of great value and significance to study spare parts allocation optimization and inventory control models under different maintenance strategies. With the continuous installation of new equipment, the generalization degree of components of various devices is improving too. It is necessary to study the influence of the commonality of spare parts on its configuration optimization programs. Corrective maintenance is a widely adopted strategy for spare parts maintenance. It is also an important object to study configuration optimization of spare parts multi-echelon. The research foundation is derived from the METRIC model proposed by Sherbrooke, and the theoretical basis is static Palm theorem[1]. Although multi-echelon configuration optimization research based on the theory is very extensive, the literatures [2-5] study demand fitting distribution, constructing objective function optimization algorithm, and other aspects deeply, according to the problem of the spare parts allocation of high dimension, nonlinear, multi-objective and so on. However, few scholars have studied the configuration optimization of general spare parts. The literature[6] has established the purchasing decision model of component commonality by introducing the important degree of spare parts, but does not consider the multi-echelon inventory problem. In the actual process of equipment support, the proportion of commonality is gradually increasing. In the study of spare parts allocation, the factors must be included in the model. The improved multi-echelon configuration model is presented, which based on component commonality in this paper. And marginal optimization algorithm is used to solve the model to get the optimal configuration program.

\section{MULTI-ECHELON INVENTORY MODEL FOR COMPONENT COMMONALITY}

\section{A. Spare Parts Demand Rate Model}

The demand rate of spare parts $\mathrm{LRU}_{j}$ in one site is $\lambda_{j(n, m)}$, $m \quad(m=1,2, \cdots, M)$ is the protection of site number, $j=1,2, \cdots, J$ is the number of spare parts, $n(n=1,2,3)$ is the protection of the level number, $n=1$ is depot level site, $n=2$ is intermediate level site, $n=3$ is the crew level site; fault isolation rate of $\mathrm{SRU}_{j k}$ is $q_{j k(n, m)}, \lambda_{j k(n, m)}$ is the demand rate on the crew level site $m$ of $\operatorname{SRU}_{j k}(m \in \operatorname{Echelon}(N))$.

$$
\lambda_{j k(n, m)}=\left\{\begin{array}{cc}
\sum_{j=1}^{J} \lambda_{j(n, m)}\left(1-\operatorname{NRTS}_{j(n, m)}\right) q_{j k(n, m)} & 1 \leq k \leq z \\
\lambda_{j(n, m)}\left(1-N R T S_{j(n, m)}\right) q_{j k(n, m)} & \mathrm{z}+1<k \leq K
\end{array}\right.
$$

$N R T S_{j(n, m)}$ is the probability that a failure of $\mathrm{LRU}_{j}$ can not be repaired at the site $m$. For $m,(m \notin \operatorname{Echelon}(N))$

$$
\lambda_{j(n, m)}=\sum_{l \in U \operatorname{Unit}(m)} \lambda_{j(l, m)} \cdot N R T S_{j(l, m)}
$$


$\lambda_{j k(n, m)}= \begin{cases}\sum_{l \in \operatorname{Unit}(m)} \lambda_{j k(l, m)} \cdot N R T S_{j k(l, m)}+\sum_{j=1}^{J} \lambda_{j(n, m)}\left(1-N R T S_{j(n, m)}\right) q_{j k(n, m)} & 1 \leq k \leq z \\ \sum_{l \in \operatorname{Unil}(m)} \lambda_{j k(l, m)} \cdot N R T S_{j k(l, m)}+\lambda_{j(n, m)}\left(1-N R T S_{m j}\right) q_{j k(n, m)} & z+1<k \leq K\end{cases}$

$N R T S_{j k(l, m)}$ is the probability that failure $\mathrm{SRU}_{j k}$ cannot be repaired at the lower level site $\mathrm{m}$; $\operatorname{Unit}(m)$ is the lower level site of the site.

\section{B. Correction of the Mean and Variance of Supply Channels for Spare Parts}

The availability of warship equipment is mainly affected by the shortage of spare parts, and the shortage number of spare parts is closely related to maintenance. Therefore, the key of modeling is to determine the mean and variance of spare parts supply channels. Through the survey, it has been found that the channels include the number of repairs, the number of recharge and the number of maintenance delays [7].

(1) the number of failure parts in repair

At any time in the steady state, the number of fault $\mathrm{LRU}_{j}$ and $\mathrm{SRU}_{j k}$ repairs at a site $\mathrm{m}$ are respectively

$$
\begin{gathered}
E\left[X_{j(n, m)}^{R}\right]=\lambda_{j(n, m)}\left(1-\operatorname{NRTS}_{j(n, m)}\right) T_{j(n, m)} \\
E\left[X_{j k(n, m)}^{R}\right]=\lambda_{j k(n, m)}\left(1-N R T S_{j k(n, m)}\right) T_{j k(n, m)}
\end{gathered}
$$

$T_{j(n, m)}$ and $T_{j k(n, m)}$ are the average repair time for the failure $\mathrm{LRU}_{j}$ and $\mathrm{SRU}_{j k}$ at the site m respectively:

$$
T_{j(n, m)}=\frac{\sum_{k=1}^{K} \lambda_{j k(n, m)} T_{j k(n, m)}}{\sum_{k=1}^{K} \lambda_{j k(n, m)}}
$$

(2) the amount of recharge

The amount of recharge are the supply number of spare parts from the superior site to the site $\mathrm{m}$ and the number of spare parts in the transportation process, and the quantity of the delayed supply which is not enough for the superior site's existing stock.

$$
E\left[X_{j(n, m)}^{S}\right]=\lambda_{j(n, m)} \operatorname{NRTS}_{j(, m)} O_{j(n, m)}+f_{j(n, m)} \mathrm{EBO}_{j(n-1, m)}
$$

Then we have

$$
f_{j(n, m)}=\frac{\lambda_{j(n, m)} \operatorname{NRTS}_{j(n, m)}}{\sum_{m=1}^{M} \lambda_{j(n, m)}}
$$

(3) the number of maintenance delays caused by maintenance

This value is equal to the sum of $\mathrm{SRU}_{j k}$ and its shortage number $\mathrm{EBO}_{j k(n, m)}$, that is,

$$
\begin{array}{r}
E\left[X_{j(n, m)}^{D}\right]=\sum_{k=1}^{K} h_{j k(n, m)} \mathrm{EBO}_{j k(n, m)} \\
h_{j k(n, m)}=\frac{\lambda_{j(n, m)}\left(1-N R T S_{j(n, m)}\right) q_{j k(n, m)}}{\lambda_{j k(n, m)}}
\end{array}
$$

In summary, the mean of supply channels $E\left[X_{j(n, m)}\right]$ for spare parts $\mathrm{LRU}_{j}$ at the site $\mathrm{m}$ is as follows:

$$
\begin{aligned}
E\left[X_{j(n, m)}\right] & =E\left[X_{j(n, m)}^{R}\right]+E\left[X_{j(n, m)}^{S}\right]+E\left[X_{j(n, m)}^{D}\right] \\
& =\lambda_{j(n, m)}\left(1-N R T S_{j(n, m)}\right) T_{j(n, m)}+\lambda_{j(n, m)} \operatorname{NRTS}_{j(n, m)} O_{j(n, m)} \\
& +f_{j(n, m)} \operatorname{EBO}_{j(n-1, m)}+\sum_{k=1}^{K} h_{j k(n, m)} \operatorname{EBO}_{j k(n, m)}
\end{aligned}
$$

When a site $\mathrm{m}$ applies for a spare part to a higher level site, the probability of a delay by a higher level site supplying to the site $\mathrm{m}$ is subject to binomial distribution. Therefore, the variance $\operatorname{Var}\left[X_{j(n, m)}\right]$ of the supply channel for the spare parts $\mathrm{LRU}_{j}$ of the site $\mathrm{m}$ is as follows

$$
\begin{aligned}
\operatorname{Var}\left[X_{j(n, m)}\right] & =\lambda_{j(n, m)}\left(1-N R T S_{j(n, m)}\right) T_{j(n, m)}+\lambda_{j(n, m)} N R T S_{j(n, m)} O_{j(n, m)} \\
& +f_{j(n, m)}\left(1-f_{j(n, m)}\right) \operatorname{EBO}_{j(n-1, m)}+f_{j(n, m)}^{2} \operatorname{VBO}_{j(n, m)} \\
& +\sum_{k=1}^{K} h_{j k(n, m)}\left(1-h_{j k(n, m)}\right) \mathrm{EBO}_{j k(n, m)}+\sum_{k=1}^{K} h_{j k(n, m)}^{2} \operatorname{VBO}_{j k(n, m)}
\end{aligned}
$$

$\mathrm{VBO}_{j k(n, m)}$ is the variance of the shortage spare parts, the specific calculation method can be referred in paper[8].

\section{Optimization MODEL OF SPARE PARTS}

Effectiveness parameters of ship equipment support commonly include availability, satisfaction rate, utilization rate, delay time, and so on [9].

The availability of equipment is obtained by [1], which combined with the structure of the equipment and the multilevel inventory system. 


$$
A=\frac{\sum_{m=1}^{M} N_{(3, m)} A_{(3, m)}}{\sum_{m=1}^{M} N_{(3, m)}}=\frac{\sum_{m=1}^{M} N_{(3, m)} \prod_{j=1}^{J}\left(1-\operatorname{EBO}_{j(3, m)} /\left(N_{(3, m)} Z_{j}\right)\right)^{Z_{j}}}{\sum_{m=1}^{M} N_{(3, m)}}
$$

$Z_{j}$ is single number of $\mathrm{LRU}_{j}, N_{(3, m)}$ is the equipment number of crew level site $\mathrm{m}$.

The satisfaction rate of the spare parts system is

$$
\mathrm{FR}=\frac{\sum_{m=1}^{M} N_{(3, m)} \mathrm{FR}_{(3, m)}}{\sum_{m=1}^{M} N_{(3, m)}}
$$

$\mathrm{FR}_{(3, m)}$ is satisfaction rate of spare parts at the crew level site $\mathrm{m}$, and can be obtained by the following formula,

$$
\mathrm{FR}_{(3, m)}=\frac{\sum_{j=1}^{J} \sum_{X_{j(3, m)}=0}^{s_{j(3, m)}-1} \lambda_{j(3, m)} p\left(X_{j(3, m)}\right)}{\sum_{j=1}^{J} \lambda_{j(3, m)}}
$$

The utilization ratio of spare parts system is

$$
\mathrm{UR}=\frac{\sum_{m=1}^{M} N_{(3, m)} \mathrm{UR}_{(3, m)}}{\sum_{m=1}^{M} N_{(3, m)}}
$$

The delay time of spare parts support system is

$$
\begin{gathered}
\operatorname{MLDT}=365 \times 24 \times \frac{\sum_{m=1}^{M} N_{(3, m)} \operatorname{MLDT}_{(3, m)}}{\sum_{m=1}^{M} N_{(3, m)}} \\
\operatorname{MLDT}_{(3, m)}=\frac{\sum_{j=1}^{J} \operatorname{EBO}_{j(3, m)}}{\sum_{j=1}^{J} \lambda_{j(3, m)}}
\end{gathered}
$$

Therefore, an optimization model based on component commonality is established, that is, the cost is the optimization goal and the effectiveness is constrained.

$$
\left\{\begin{array}{l}
\min C=\sum_{m \in \operatorname{Echelon}(N)} \sum_{j=1}^{J} c_{j} S_{j(n, m)} \\
\text { s.t. } \quad A>A_{0} \quad \mathrm{FR}>\mathrm{FR}_{0} \quad \mathrm{MLDT}<\mathrm{MLDT}_{0} \quad \mathrm{UR}>\mathrm{UR}_{0}
\end{array}\right.
$$

\section{ALGORITHM OF OPTIMIZATION MODEL}

Marginal optimization algorithm is one of the most common and effective algorithms for spare parts allocation model. The principle of the algorithm is to compare spare parts marginal allocation benefits of sites, and determine spare parts location, then iterate until the model constraint condition is satisfied. Because the availability model of ship equipment is a sum function of the shortage spare parts at the crew level sites, the objective function is separable, so the objective function is convex, the marginal optimization algorithm can determine the optimal solution of every iteration[7-11]. Considering the relationship between the availability and the number of spare parts shortage, the marginal benefit for the availability of the ship equipment value is converted to marginal benefit value of the number of spare parts shortage on the crew level, which can improve the efficiency of algorithm. The concrete steps are as follows:

Step1: initialization, the initial spare parts configuration scheme $\mathrm{s}$ is 0 .

Step2: the marginal benefit value $\delta_{j(n, m)}$ of the spare parts allocation at all levels sites is increased by 1 respectively through formula (20):

$$
\delta_{j(n, m)}=\frac{\operatorname{EBO}(s)-\operatorname{EBO}\left(s+\Delta_{j(n, m)}\right)}{C_{j}}
$$

$\operatorname{EBO}(s)$ is sum of the expected spare parts shortage at crew level site under the allocation scheme $s$, $\operatorname{EBO}\left(s+\Delta_{j(n, m)}\right)$ is the expected spare parts shortage at crew level site, based on the allocation scheme $s$, it equals to number of spare parts $j$ in allocation site $(n, m)$ plus 1 .

Step3: according to the results of the Step2, the site $\delta_{j(n, m)}$ corresponding to the maximum value is selected and the configuration amount adds 1 .

Step4: the configuration plan is updated, and the availability, spare parts support probability and other parameters are calculated, the result are determined whether achieve the constraint requirements. If not, then goes to Step2, continue to iterate; if the result meets the constraints, then goes to Step5.

Step5: spare parts configuration program is outputted.

\section{EXAMPLE ANALYSIS}

Compass is the main platform of ship navigation equipment, its supply support system structure as shown in Figure I. The 
device is equipped with three crew level site, and the number are $(12,10,8)$ respectively. The purchase delay time at middle level sites are 8 days and 6 days, the purchase delay time at crew level site are 4 days, 3 days and 4 days. The configuration program of spare parts is optimized, which the system availability is 0.95 .

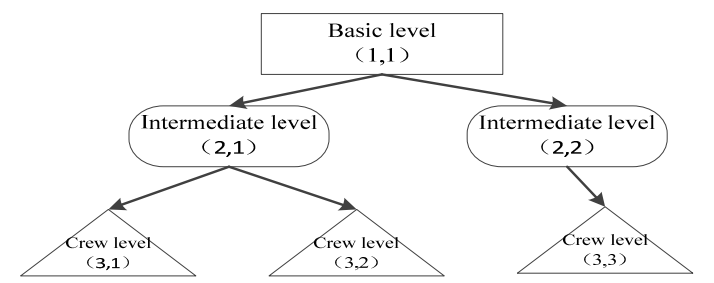

FIGURE I.

SCHEMATIC DIAGRAM OF WARSHIP EQUIPMENT STRUCTURE SYSTEM

The solution process of the configuration optimization plan is analyzed, and the cost efficiency curve for the marginal optimization algorithm is shown in Figure II.

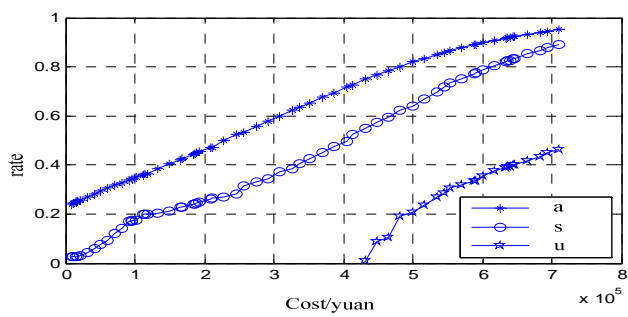

a-availability, s-satisfaction rate, u-utilization rate

FIGURE II. CURVE OF EFFECTIVENESS VS. COST FOR COMPONENT COMMONALITY

From the above chart, availability, satisfaction rate and utilization rate are increasing nonlinearly with the increase of the cost, and the availability curve has the characteristics of convexity, which reflects the marginal value is strictly monotonically decreasing with the increase of iteration, the initial value of 0.0002 is declined to , as shown in Figure III; the expected shortage value is reduced to 1.4622 from 34.7857 , but this is not strictly monotone, as shown in figure IV.

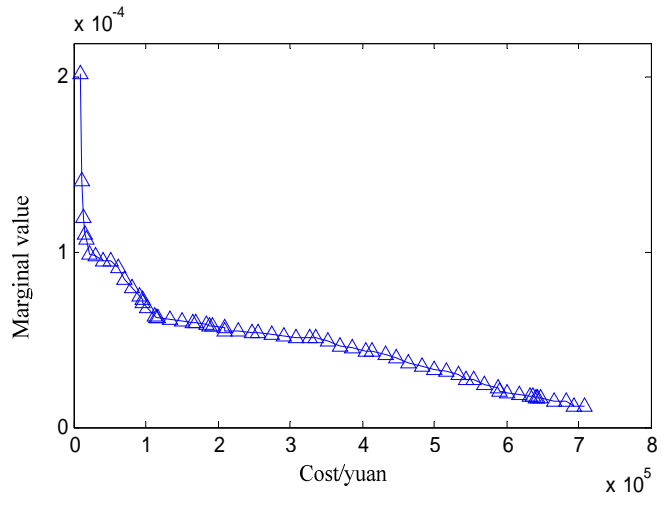

FIGURE III
THE CURVE OF MARGIN VALUE

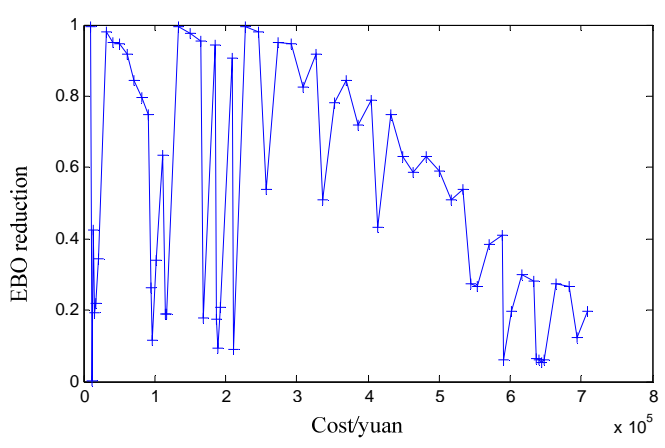

FIGURE IV. THE CURVE OF EBO REDUCTION

Figure $\mathrm{V}$ shows a marginal optimization algorithm for solving the relationship between delay time and cost.

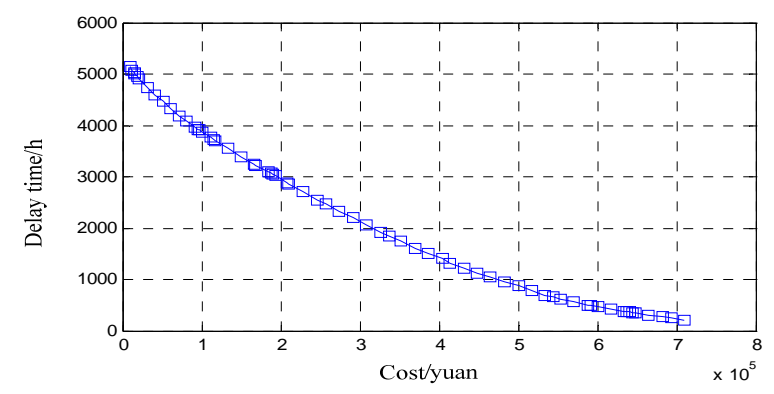

FIGURE V.

$$
\begin{aligned}
& \text { THE CURVE OF EFFECTIVENESS VS. COST FOR } \\
& \text { MLDT }
\end{aligned}
$$

From the above chart, with the cost increases, the number of spare parts is also increased, and the delay time is strictly monotonically decreased, that is from $5134 \mathrm{~h}$ to $214 \mathrm{~h}$.

\section{CONCLUSION}

In spare parts supply, the problem of component commonality exists in most equipment, and the optimization model of spare parts allocation based on component commonality is established. The result in the case shows that the problem of deviations in availability is solved by the model in the paper, which save the inventory of supply system. The evaluation precision is improved by the model in paper in case that requirement of support indexes are needed, and the total cost is reduced. Therefore, the result can provides a theoretical basis and decision support for the use of component commonality.

\section{REFERENCES}

[1] Sherbrooke Craig C. Optimal Inventory Modeling of Systems: MultiEchelon Techniques [M]. Second Edition. New York ; Springer Science Business Media, 2004

[2] Zhang Lin, Zhao Jie, Tang Chao, etc. Research on the Echelon Inventory Model of the Repairable Spares [J]. Acta ArmamentarII, 2009, 30(11): 90-94.

[3] Wang Yabin, Zhao Jianmin, Cheng Zhonghua, etc. Optimization for spare parts allocation in multi-echelon support system based on improved MOPSO [J]. System Engineering and Electronics, 2015, 37(7): 1581-1586. 
[4] Jayaraman V, Pirkul H. Planning and coordination of production and distribution facilities for multiple commodities [J]. European Journal of Operational Research, 2001, 133(2): 394-40.

[5] Wong H, Cattrysse D, Oudheusden D V. Stocking decision for repairable spares pooling in a multi-hub system [J]. International Journal of Production Economics, 2005(93): 309-317.

[6] Mao Shihong. Decision research on purchase quantity allocation for general spare parts base on importance degree [J]. Science and Technology Management Research, 2012, 13: 242-244.

[7] Ruan Minzhi, Li Qingmin, Li Cheng, etc. Improved-Layered-Marginal Algorithm to Optimize Initial Spare Part Configuration Project [J]. ACTA ArmamentarII, 2012,33(10): 1251-1256.

[8] Sherbrooke C C, Optimal inventory modeling of system: Multi-Echelon Techniques [M]. Springer. 2004.

[9] Francesco Costantino, Giulio Di Gravio,Massimo Tronci, Multi-echelon, multi-indenture spare parts inventory control subject to system availability and budget constraints [J]. Reliability Engineering \& System Safety, 2013, 119(0): 95-101.

[10] Dong Qi, Xu Tingxue, Zhao Jianzhong, etc. Multi-objective optimization configuration for special equipment materials on warship [J]. Science \&Technology Review, 2015,33(19): 96-101.

[11] Wong H., Van Houtum G.J., Cattrysse D.,Van Oudheusden D., Stocking decisions for repairable spare parts pooling in a multi-hub system [J]. International Journal of Production Economics, 2005, 93: 309-317. 